\title{
Development and Critiques of Conceptual Metaphor Theory
}

\author{
Xin Zhang \\ Shantou University, Shantou, Guangdong Province, China
}

\begin{abstract}
There is an increasing trend in revealing the effect of conceptual metaphor on activities in the context of education. In order to shed light on future studies in this field, it is necessary to review the development and critiques of conceptual metaphor theory in general and applications and previous studies under the context of education in particular. This paper defines the term "metaphor" at first and further reviews its implications in constructing the conceptualization of educational-related concepts. Problems and challenges of conceptual metaphor theory are also discussed.
\end{abstract}

Index Terms-Conceptual Metaphor Theory, metaphor analysis, critiques of conceptual metaphor

\section{INTRODUCTION}

The study of metaphor has a long history, and it can even be traced back to 1932 when Aristotle claims that metaphor is "the application of a word belonging to something else" (p.51). Also, Aristotle's views on metaphor provide insights into shaping the conceptualization of metaphors. Kövecses (2010) has identified five common characteristics of the traditional concept of metaphor:

1. Metaphor is the property of words.

2. Metaphor is used for some artistic and rhetorical purpose.

3. Metaphor is based on a resemblance between the two entities that are compared and identified

4. Metaphor is a conscious and deliberate use of words, and you must have a special talent to be able to do it well.

5. Metaphor is a figure of speech that we can do without; we use it for special effects, and it is not an inevitable

part of everyday human communication. (Kövecses, 2010, p.ix-x)

Aristotle's theory of metaphor and the associated five common features listed by Kövecses were still influential recently. Metaphors We Live By, which was written by Lakoff and Johnson in 1980, caused a dramatic shift in the field of metaphor studies. "Conceptual metaphor theory" or "Cognitive Metaphor Theory" was developed by scholars in the field of cognitive sciences to the widely accepted notion of "metaphor-as-thought" (Deignan, 2005; Todd \& Low, 2010). Besides, there is a growing literature regarding conceptual metaphor theory since Lakoff and Johnson first proposed conceptual metaphor theory in Metaphors We Live by. It elaborates the conceptual metaphor theory into cognitive science, and it points out that human thought is metaphorically constructed. They also argue that metaphor is inevitable to both thought and language. The origins of metaphor lie in embodied experience, providing the human conceptual system via the metaphorical projection of conceptual structure (Thomas, 2010, p.80).

To address the effect of conceptual metaphor on activities in the context of education, it is necessary to define the term "metaphor" at first and further review its implication in constructing the conceptualization of educational-related concepts. Problems and challenges of conceptual metaphor theory are also discussed.

\section{CONCEPTUAL METAPHOR THEORY}

\section{A. Key Concepts of Conceptual Metaphor Theory}

There are a number of aspects of metaphors, including linguistic, embodied, cognitive, affective, socio-cultural, and dynamic metaphors. Cameron (2010a) has regarded metaphor as a "multi-dimensional phenomenon" and believes that "all those dimensions can be identified in data and used in the analysis, depending on the stance of the researchers" (2010a, p.23). In general, scholars consider what linguistic metaphor is at first (Todd \& Low, 2010). The linguistic metaphor refers to 'metaphors that are found in language use' (Cameron, 2010a). The focus of metaphor varies from diverse research backgrounds or purposes, such as cognitive sciences, cultural studies, and critical discourse analysis. However, this paper focuses on the metaphor in conceptual metaphor theory.

Conceptual metaphor theory was first proposed by George Lakoff and Mark Johnson in the renowned book Metaphors We Live by in 1980. Before they proposed this innovational idea of metaphors, metaphor is generally recognized as purely figurative language or a matter of words or linguistic expressions, rather than thought or minds. Given linguistic and sociological evidence from the collections of different sources (such as LIFE IS A JOURNEY, ARGUMENT IS WAR, and ANGER IS FIRE), Lakoff and Johnson (1980) believe that 'our ordinary conceptual system, in terms of which we both think and act, is fundamentally metaphorical in nature (p.4). In every dimension of our life, we conceptualize reality through metaphors and therefore respond based on those metaphors (Lakoff \& 
Johnson, 2003). This is due to the reason that we construct our experiences consciously or unconsciously through metaphor. It means that metaphor is an unavoidable process of human thought and reasoning. Moreover, they even propose that "the essence of metaphor is understanding and experiencing one kind of thing in terms of another" (2003, p. 6). That is, therefore, the notion of "conceptual metaphor" as a mapping between two domains in the conceptual system' (Cameron, 2010a, p.5). Conceptual metaphor theory (CMT) lies in the connection between the body and the world to clarify the underlying structure of the mind. Based on Thomas (2010), those structures "form the skeletal framework that allows metaphoric linkages between concepts and categories to take place, providing the basis for abstract reasoning and deliberation" (p.79). In that case, metaphor is regarded as a way of conceptualizing the world.

The CMT theory claims that "metaphor is central to thought, and therefore to language" (Deignan, 2005 p.13). Besides, the central claim of CMT is that "metaphor operates at the level of thinking" (Deignan, 2010, p.44). Lakoff and Johnson (1999) further propose three key statements regarding conceptual metaphor in Philosophy in the flesh: 1) human thought is embodied, 2) human thought is automatic and unconscious in the majority of the time, 3) the majority of abstracts are metaphorical. Besides, the CMT position holds that metaphor fundamentally shapes and alters human conceptual structures, thereby affecting how we experience (Thomas, 2010, p.79). The fundamental premise of CMT is that our conceptual system is metaphoric and the basis for our conceptual system is grounded in the embodied experience (Lakoff \& Johnson, 1980, 2003; Lakoff, 1993, Gibbs, 2006).

According to Kövecses (2002), conceptual metaphors employ a more abstract concept as a target and a more concrete or physical concept as their source. This is due to the fact that concrete concepts offer a more clear explanation of abstract concepts and then result in better understanding. In other words, the source domain is adopted to conceptualize the target domain. The structure of conceptual domains is mapped from the concrete to the abstract, allowing rich understandings of concepts outside of direct experience to be formed (Thomas, 2010, p.80). In addition, our experiences with the physical world serve as natural and logical foundations for the comprehension of more abstract domains (Kövecses, 2002, p.6). Therefore, the metaphor has been recognized as a cognitive tool, which is used to understand complex concepts and ideas. From the CMT perspective, metaphor plays an essential role in facilitating understanding through the process of transforming the concrete physical experience from abstract domains. The essence lies in the cognitive processes of linking two domains (Lakoff, 1993). In our endeavor to comprehend this world, metaphors facilitate in conceptualizing "the cognitively less easily accessible domains in terms of the more easily accessible ones" (Kövecses, 2020, p.5).

Deignan (2005) summarized the major tenets which derived from the conceptual metaphor theory as following: Metaphors structure thinking; metaphors structure knowledge; metaphor is central to abstract language; metaphor is grounded in physical experiences; metaphor is ideological (Deignan, 2005, p. 13).

\section{B. Challenges of Conceptual Metaphor Theory}

In the past several decades, there is an emergent literature challenge or criticism for Lakoff and Johnson's theory of conceptual metaphor within as well as outside of cognitive linguistics (Cameron, 2007, 2010b; Ritchie, 2010; Gibbs, 2011). Therefore, Kövecses (2020) proposes a more technical definition of conceptual metaphors as follows: "a conceptual metaphor is a systematic set of correspondences between two domains of experience" (p.2). The initial definition of conceptual metaphors made by Lakoff and Johnson (1980) is that "A conceptual metaphor is understanding one domain of experience in terms of another." In contrast to the definition proposed by Lakoff and Johnson (1980), he uses "two domains of experience" to replace "understanding one domain in terms of another" and uses "correspondence" instead of "mapping". This is due to the fact that "the two-domain account does not work and must be supplemented by a model of explanation that relies on four (or more) domains, or spaces” (Zoltán, 2020, p.1). Furthermore, conceptual metaphors cannot always be mapped from the source domain to the target domain.

\section{METAPHOR ANALYSIS}

Although metaphor analysis is widely used across various disciplines beyond linguistics, approaches or methods toward metaphor analysis are not always clear due to the various research purposes or focuses. The way a metaphor analysis is conducted differently based on "research questions, the theories selected to underpin the work and practical aspects of the situation" (Low \& Todd, 2010, p.40). Todd and Low (2010) have analyzed six papers from education and health disciplines and have summarized the general process of metaphor analysis.

In most cases, researchers group metaphors into similar kinds, and the analysis usually focuses on the higher-level groupings rather than the individual metaphors. The higher-level metaphors are usually the feature of most interest to researchers, particularly when the investigation is on the use of metaphor as a framing device. (Todd \& Low, 2010, p. 40)

Metaphor analysis is a systematic approach to analyze the metaphors which people utilized in expressing themselves or delivering points (Pitcher \& Akerlind, 2007). It is a sophisticated method of understanding people's beliefs or ideas because it always uncovers "the metaphorical nature of our activities" (Lakoff \& Johnson, 2003, p.8).

A large number of researchers have adopted the metaphor analysis developed by Cameron and Low in 2009. One way of metaphor analysis is "collecting examples of linguistic metaphors used to talk about the topic... generalizing from them to the conceptual metaphors they exemplify, and using the result to suggest understandings or thought 
patterns which construct or constrain people's beliefs or actions" (Cameron \& Low, 2009, p.88). In short, metaphor analysis is grouping linguistic metaphors into conceptual categories. The general procedures are as follows:

(a) collecting informants' metaphorical linguistic expression (MLE) of the topic,

(b) generalizing from MLEs to the conceptual metaphors they exemplify,

(c) using the results to suggest understanding or thought patterns that construct or constrain people's beliefs or

actions. (Cameron \& Low, 1999, p.8)

There are several ways of collecting initial data concerning metaphors. One way is identifying the linguistic metaphors from discourse (Cameron \& Maslen, 2010; Cameron, et al. 2010) while the other way is using $A$ is $B$ format to collect metaphorical linguistic expression (Wan et al., 2010). The Pragglejaz group also has worked to develop empirical investigative tools for metaphor research, named MIP (Metaphor Identification Procedure), in nature discourse.

\section{APPLICATION OF METAPHOR ANALYSIS IN EDUCATION}

Metaphors make things exciting and understandable and, as such, have been applied to education since time immemorial (Low, 2008, p. 212). In particular, the last several decades have witnessed considerable investigation into metaphor as a tool for the in-depth understanding of teachers' conceptualizations about the school, teaching, and curriculum. Educational concepts and processes have long been described in metaphorical terms either as single ' $\mathrm{X}$ is $\mathrm{Y}^{\prime}$ metaphors (e.g. EDUCATION IS PREPARING MENTAL MEALS; LEARNING IS POURING WATER INTO A JUG) or as clusters of metaphors (Low, 2008, p. 213). Metaphors, as Cortazzi and Jin (1999) suggest, offer solutions in understanding or even shaping a variety of disciplines and educational issues.

A considerable literature has illustrated that metaphors are facilitating the understanding of how both teachers and prospective teachers conceptualize relevant concepts in educational settings (e.g., Brown et al., 2005; Batten, 2012). Also, an increasing number of researchers have identified the foundational position of metaphor analysis in the field of teacher identity, for gaining insight into teachers' images of teaching and learning (Shaw \& Mahlios, 2008; Wan et al., 2011). Besides, metaphors are used to understand particular disciplines and design relevant pedagogical implications (Amin, 2015; Daane, et al., 2016; Xu \& Liu, 2013). Amin (2015) reviewed the previous studies on conceptual metaphors in science education and identify "the natural theoretical connections between the conceptual metaphor perspective and the phenomenon of conceptual change" (p.966). Amin (2015) believed that conceptual change which is identified and examined from the study could offer clues in improving teaching practice. Similarly, teachers' metaphorical expressions of teaching could be served as a method of examining teaching practice (Connelly \& Clandinin, 1998). Metaphors can also be utilized to analyze recently emerged area, like Mobile Assisted Language Learning (MALL). In the study conducted by Meng, Ma, and Yue in 2018, metaphors are employed to facilitate an understanding of college students' characteristics of perceptions toward MALL, with a particular focus on learners' cognitive engagement.

\section{CRitiques of CONCEPTUAL Metaphor}

Although Conceptual Metaphor Theory has been widely accepted as the most influential theory regarding metaphor and it has been adopted in many disciplines including linguistics, psychology, education, and so on, it has received strong critiques from diverse perspectives (McGlone, 2007, 2011; Ruiz de Mendoza Ibáñez \& Perez Hernandez, 2011). Those criticisms are including "the methodology with which metaphor is studied (emphasizing concepts instead of words), the direction of analysis (emphasizing a top-down instead of a bottom-up approach), the category level of metaphor (claiming its superordinate status instead of basic level), the embodiment of metaphor (emphasizing the universal, mechanical, and monolithic aspects instead of nonuniversal, nonmechanical, and nonmonolithic aspects of embodiment), and its relationship to culture (emphasizing the role of universal bodily experience instead of the interaction of boy and the context)" (Kövecses, 2008, p.168). Besides, he have argument with other three main criticism against conceptual metaphor theory from a methodological perspective in 2011, including "(1) the idea that practitioners of "traditional" conceptual metaphor theory use intuitive metaphor analyses; (2)the notion that such researchers do not pay sufficient attention to the highly irregular character of linguistic metaphors; and (3) the claim that these researchers work with highly impoverished collections of metaphors" (Kövecses, 2011, p.23). Moreover, McGlone (2007) proposes a three-step challenge for conceptual metaphor theory.

In repose to that criticism, Gibbs $(2011)$ and Kövecses $(2011,2020)$ have adopted linguistic and psychological evidence to defend conceptual metaphor theory. The original evidence for conceptual metaphor originates from the systematic analysis of conventional expressions in diverse languages (Lakoff \& Johnson, 1980, 1999; Kövecses, 2002). In addition, hundreds of conceptual metaphors have been identified based on "cognitive linguistic analyses of conventional expression, novel extensions, and polysemy" (Kövecses, 2002; Lakoff \& Johnson, 1999; Yu, 1999; cited from Gibbs, 2011).

One of the most often claimed concerns towards conceptual metaphor theory is focused on the methodology of identifying linguistic metaphors. Moreover, they even argue that most scholars in the area of conceptual metaphor set up conceptual metaphors based on intuition. In that case, it is doubtful in procedure since whether scholars have 
adopted the same or any explicit criteria in making judgments concerning systematicity and conceptual metaphors (Pragglejaz Group, 2007; Gibbs, 2011). This critique concentrates on two aspects: 1) whether the judgments are reasonable or not; 2) whether notice the actual expressions which are used for the target domain in context or natural discourse. In response to this critic, Kövecses (2011) argues that based on the three levels of the existence of metaphors can be identified in a cognitive linguistic approach.

"The goals of the two levels (individual level and supra individual level) complement each other, in that the metaphors suggested on an intuitive basis may prove to be useful in organizing the systematically identified linguistic metaphors into "larger" conceptual metaphors used at the individual level and, also because the systematically identified linguistic metaphors in real discourse may lead to the discovery of so far identified conceptual metaphors."(Kövecses, 2011, p.169-170)

Several metaphor-analysis oriented researches have reported the frequency of invalid responses to some extent. What's worse, some scholars have found out that participants had problems in finishing researcher-constructed prompts or elicited metaphors (Wan, 2011; Eren \& Tekinarslan, 2013). In general, the criteria for failed responses relate to the following dimensions: (a) no answer, (b) no metaphor, or (c) the metaphor could not be compatible with a conceptual theme (Wan, 2011). For example, the study which has been conducted by Eren and Tekinarslan in 2013 concerning prospective teachers' beliefs of instructional materials and evaluation concepts has a quite low rate of successful metaphors. They have collected 4351 metaphors, in which only 1260 responses provided valid metaphors. In other words, only $28 \%$ of the responses were met the criteria. Besides, Meng, Ma and Yue (2018) also reported failure elicited metaphors, with only 3090 out of 7000 elicited metaphors are valid. It means that around $44 \%$ were met the criteria of valid metaphors.

To reduce the risk of task failure, training workshops involve with basic knowledge of metaphors should be offered as well as a sample of elicited metaphors. More importantly, it is essential that the decontextualized researcher-constructed prompts which enhance the creation of metaphor to avoid failure in elicited metaphor analysis (Wan, 2011).

Besides the aforementioned problems, there are several issues in eliciting metaphors and identifying metaphors. When investigating the cognitive models concerning metaphor, the researcher should avoid mental overload for participants to ensure that they are not giving unrealistic judgments. If using A is B format to present figurative language, researchers should also check whether it is as representative for linguistic metaphors as for similes (Low \& Todd, 2010). When analyzing metaphors and metaphors in the discourse, in particular, reliability and validity checks should be adopted (Pragglejaz group, 2007).

Based on the problems and issued have identified from the previous studies, Low and Todd (2010) have further summarized the main features of a metaphor analysis:

- recognizing that metaphoricity can be complex, indeterminate, and unstable;

- Admitting the problems and treating one's solutions as compromises;

- Knowing what the compromises entail;

- Telling the reader how/why one arrived at conclusions and admitting the limitations of one's conclusions.

(Low \& Todd, 2010, p. 218)

In conclusion, metaphor is an extremely complicated mental event and it is not an easy topic to research empirically since it is hard to "develop a consistent and explicit identification procedure" (Low \& Todd, p. 229). The interpretation of metaphors might be fuzzy, linguistically biased, or unrepresentative. If possible, validation should be taken into account. Even so, the conceptual metaphor still shed lights on the integration of embodiment, language, thought, and culture which leads to holistic incorporation of metaphor studies in cognitive science (Kövecses, 2011) and offers insights into other disciplines, like the educational field, by using it to explore understanding or conceptualization of certain concepts (Low, 2008; Wan, et al.2011).

\section{REFERENCES}

[1] Amin, T. G. (2015). Conceptual metaphor and the study of conceptual change: Research synthesis and future directions. International Journal of Science Education, 37(5-6), 966-991.

[2] Aristotle., \& Cooper, L. (1932). The rhetoric of Aristotle. Appleton.

[3] Batten, A. J. (2012). Metaphors we teach by: the language of "learning outcomes". Teaching Theology and Religion, 15 (1), $16-28$.

[4] Brown, P.U., Parsons.S. U. \& Worley, V. (2005). Pre-service teachers write about diversity: a metaphor analysis. Scholar-practitioner Quarterly, 3(1), 87-102.

[5] Cameron, L. (2007). Patterns of metaphor use in reconciliation talk. Discourse and Society. 18(2):197-222.

[6] Cameron, L., \& Low, G. (1999). Metaphor. Language Teaching, 32, 77-96.

[7] Cameron, L. (2010a). What is metaphor and why does it matter? In Cameron, L. \& Maslen, R., Ed., Metaphor analysis. London: Equinox, pp.3-25.

[8] Cameron, L. (2010b). The discourse dynamics framework for metaphor. In Cameron, L. \& Maslen, R., Ed., Metaphor analysis. London: Equinox, pp.77-94.

[9] Cameron, L. \& Maslen, R. (2010). Identifying metaphors in discourse data. In Cameron, L. \& Maslen, R., Ed., Metaphor analysis. London: Equinox, pp.97-115. 
[10] Cameron, L., Maslen, R. \& Low, G. (2010). Finding systematicity in metaphor use. In Cameron, L. \& Maslen, R., Ed., Metaphor analysis. London: Equinox, pp.116-146.

[11] Cortazzi, M., Jin, L. (1999). Bridges to learning: metaphors of teaching, learning, and language. In: Cameron, L., Low, G.D. (Eds.), Researching and applying metaphor. Cambridge University Press, Cambridge, pp.149-176.

[12] Daane, A. R., Haglund, J., Robertson, A. D., Close, H. G., \& Scherr, R. E. (2018). The pedagogical value of conceptual metaphor for secondary science teachers. Science Education, 102(5), 1051-1076.

[13] Deignan, A. (2005). Metaphor and corpus linguistics (Vol. 6). John Benjamins Publishing.

[14] Deignan, A. (2010). The cognitive view of metaphor: Conceptual metaphor theory. In Cameron, L. \& Maslen, R., Ed., Metaphor analysis. London: Equinox, pp.44-56.

[15] Eren, A., \& Tekinarslan, E. (2012). Prospective Teachers' Metaphors: Teacher, Teaching, Learning, Instructional Material and Evaluation Concepts. International Journal of Social Sciences \& Education, 3(2), 435-445.

[16] Gibbs, R. (2006). Embodiment and cognitive science. New York: Cambridge University Press.

[17] Gibbs, R. (2011). Evaluating conceptual metaphor theory. Discourse processes, 48(8), 529-562.

[18] Kövecses, Z. (2002). Metaphor: a practical introduction. Oxford: Oxford University Press.

[19] Kövecses, Z. (2008). Conceptual metaphor theory: Some criticisms and alternative proposals. Annual review of cognitive linguistics, 6(1), 168-184.

[20] Kövecses, Z. (2010). Metaphor: A practical introduction. Oxford University Press.

[21] Kövecses, Z. (2011). Methodological issues in conceptual metaphor theory. In Handl, S., \& Schmid, H. J. (Eds.), Windows to the Mind: Metaphor, Metonymy and Conceptual Blending. New York: Walter de Gruyter, pp.23-40.

[22] Kövecses, Z. (2020). Extended Conceptual Metaphor Theory. Cambridge University Press.

[23] Lakoff, G. (1993). The contemporary theory of metaphor. Metaphor and thought, $2^{\text {nd }}$ edition. (pp.202-251). Cambridge, Cambridge University Press

[24] Lakoff, G., \& Johnson, M. (1980). Metaphor we live by. Chicago/London.

[25] Lakoff, G., \& Johnson, M. (1999). Philosophy in the flesh: The embodied mind and its challenge to western thought (Vol. 640). New York: Basic books.

[26] Lakoff, G., \& Johnson, M. (2003). Metaphor we live by. Chicago: University of Chicago Press.

[27] Low, G. (2008). Metaphor and education. In R. Gibbs (Ed.), Cambridge handbook of metaphor and thought. Cambridge: Cambridge University Press, pp. 212-230.

[28] Low, G. \& Todd, Z. (2010). Good practice in metaphor analysis: Guidelines and pitfalls. In Cameron, L. \& Maslen, R., Ed., Metaphor analysis. London: Equinox, pp.218-229.

[29] McGlone, M. (2007). What is the explanatory value of a conceptual metaphor? Language \& Communication, 27, $109-126$.

[30] McGlone, M. S. (2011). Hyperbole, homunculi, and hindsight bias: An alternative evaluation of conceptual metaphor theory. Discourse Processes, 48(8), 563-574.

[31] Meng, Y., Ma, X., \& Yue, Z. (2018). Da xue sheng yi dong yu yan xue xi de ren zhi te zheng. [College students' perceptions on MALL: Evidence from metaphor.]. Wai уи уи wai yи jiao хие. (5), 129-138.

[32] Pitcher, R. \& Akerlind, G.S. (2009). Post-doctoral researchers' conceptions of research: a metaphor analysis. International Journal for Researcher Development, 1(2). 160-172.

[33] Pragglejaz group. (2007). MIP: A method for identifying metaphorically-used words in discourse. Metaphor and Symbol. 22(1):1-40.

[34] Ruiz de Mendoza Ibáñez, F. J., \& Perez Hernandez, L. (2011). The contemporary theory of metaphor: Myths, developments and challenges. Metaphor and symbol, 26(3), 161-185.

[35] Shaw, D. M., \& Mahlios, M. (2008). Pre-service teachers' metaphors of teaching and literacy. Reading Psychology, 29(1), 31-60.

[36] Thomas, B. A. (2010). Complicating metaphor: Exploring writing about artistic practice through Lacanian psychoanalytic theory and conceptual metaphor theory (Doctoral dissertation, The Ohio State University).

[37] Todd, Z. \& Low, G. (2010). A selective survey of research practice in published studies using metaphor analysis. In Cameron, L. \& Maslen, R., Ed., Metaphor analysis. London: Equinox, pp.26-41.

[38] Wan, W., Low, G, \& Li, M. (2011). From students' and teachers' perspectives: Metaphor analysis of beliefs about EFL teachers' roles. System, 39(3), 403-415.

[39] Wan, W. (2011). An examination of the validity of metaphor analysis studies: Problems with metaphor elicitation techniques. Metaphor and the Social World, 1 (2), 262-288.

[40] Xu, Y. \& Liu, Y. (2013). Teachers assessment knowledge and practice: a narrative inquiry of a Chinese college EFL teacher's experience. TESOL Quarterly, 43(3), 493-513.

[41] Yu, N. (1999). The contemporary theory of metaphor: A perspective from Chinese. Amsterdam, the Netherlands: Benjamins.

Xin Zhang, Lecturer, English Language Center, College of Liberal Arts, Shantou University, China. Her major research areas cover metaphor in educational discourse and written corrective feedback. 